\title{
EFEKTIFITAS PENGARUH SOCIAL SKILL TRAINING DALAM MENURUNKAN PERILAKU ISOLASI SOSIAL REMAJA KORBAN BULLYING DI SMK AHMAD YANI PROBOLINGGO
}

\author{
Rizka Yunita, Wisnu Barlianto, Rinik Eko Kapti \\ Program Studi Magister Keperawatan Fakultas Kedokteran Universitas Brawijaya \\ E-mail : rizkayunita10@gmail.com
}

\begin{abstract}
Bullying is common especially when entering adolescence. However, if bullying is done continuously causes the negative impact such as anxiety, shame, low confidence, and anxiety. Those impacts encourage them to isolate themselves from the social environment. An effort that can be done to handle the situation is to provide Social Skill Training. This therapy teaches social skills through basic communication techniques, verbal and non-verbal, to express their thoughts and feelings well. The purpose of this research is to analyze the effectivity of SST on the decrease of social isolation behavior among teenagers who become the victims of bullying. This research uses quasy experimental with pre post-test design. The technique to determine the sample is using purposive sampling in the class $X$ students who experienced social isolation behavior due to bullying. The total sample used was 18 respondents. According to univariate test, the result got that social isolation behavior score before given SST equal to 79,11 while after given SST equal to 58,83. Whereas, paired t-test showed that there were differences of social isolation behavior score before and after given SST intervention which had significant value equal to $\rho=0,000$. This research hopes that there will be interventions given to families, schools and peers through supportive therapy in order to provide support to the bullying teens.
\end{abstract}

Keywords : SST, social isolation behavior, bullying

\begin{abstract}
Abstrak : Bullying saat ini marak terjadi terutama saat memasuki usia remaja. Apabilabullying dilakukan terus menerus dapat menimbulkan kecemasan, malu, menurunkan kepercayaan diri, dan gelisah sehingga mendorong mereka untuk mengisolasi diri dari lingkungan sosial. Salah satu upaya yang dapat dilakukan untuk menangani situasi tersebut adalah memberikan Social Skill Training. SST mengajarkan keterampilan sosial melalui teknik komunikasi dasar secara verbal dan non verbal sehingga mampu mengutarakan pikiran dan perasaannya dengan baik. Tujuan penelitian ini adalah menganalisis efektifitas pengaruh SST dalam menurunkan perilaku isolasi sosial remaja korban bullying.Penelitian ini menggunakan desain quasyexperimental dengan pre-post testdesign. Teknik penentuan sampel menggunakan purposive sampling pada siswa kelas $\mathrm{X}$ yang mengalami perilaku isolasi sosial akibat bullying. Total sampel yang digunakan sebanyak 18 responden. Berdasarkan hasil uji univariat didapatkan bahwa skor perilaku isolasi sosial sebelum diberikan SST sebesar 79,11 sedangkan sesudah diberikan SST sebesar 58,83. Sementara itu, hasil uji $t$-test berpasangan menunjukkan bahwa terdapat perbedaan skor perilaku isolasi sosial sebelum dan sesudah diberikan intervensi SST mempunyai nilai signifikansi sebesar $\rho=0,000$. Hal ini berarti bahwa intervensi SST signifikan menurunkan perilaku isolasi sosial. Penelitian ini mengharapkan terdapat pemberian intervensi kepada keluarga, sekolah, dan teman sebaya melalui terapi suportif sehingga dapat memberikan dukungan kepada remaja korban bullying didalam menurunkan perilaku isolasi sosial.
\end{abstract}

Kata kunci: SST, Perilaku Isolasi Sosial, Bullying

\section{PENDAHULUAN}

Tindakan bullying saat ini telah marak menjadi perbincangan utama diseluruh dunia terutama ketika memasuki usia remaja (Shafer \& Silverman, 2013; Srisiva, Thirumoorthi \& Sujatha, 2013). Seperti yang diungkapkan oleh Turkmen et al (2013) bahwa kejadian bullying pada siswa tingkat SMA di Turki telah mencapai 96,7\%. Peristiwa serupa juga dialami di Indonesia seperti yang dipaparkan Karina, Hastuti dan Alfiasari (2013) menguraikan perilaku bullying di Surabaya telah mencapai $67,9 \%$ tingkat SMA.

Tindakan bullying dilakukan dengan alasan yaitu menjaga eksistensi diri di sekolah sehingga mereka tidak mempunyai saingan lagi secara fisik, prestasi dan sosial (Cookdkk, 2010). Pelaku bullying memperlakukan korbannya dengan berbagai cara seperti mencemooh, 
intimidasi, menyebarkan rumor dan kebohongan mencapai (59\%), mengasingkan korban bully dari kelompok (14\%), merusak barang dengan sengaja, mendorong, dan memukul (11\%), bertindak keras dalam bentuk verbal bahkan memberikan ancaman yang dapat membahayakan nyawa $(9 \%)$ serta melakukan kekerasan secara psikologis mencapai (7\%) (Srisiva, Thirumoorthi dan Sujatha, 2013).

Bullying mempunyai dampak negatif yakni menimbulkan cemas, gelisah, malu, dan tidak percaya diri ketika berinteraksi dengan orang lain sehingga mereka membatasi serta menarik diri dari lingkungan sosial. Pernyataan tersebut sesuai dengan hasil penelitian dari AlSaadoon et al., (2014) menyebutkan bahwa korban bullying mengalami isolasi sosial mencapai $28,7 \%$ yang ditunjukkan dengan bersikap pasif terhadap lingkungan sekitar sebesar 54\% (Thornberg, 2010).

Pembatasan interaksi dilakukan korban bullying karena mereka mengalami perubahan kognisi kognitif yang memandang diri secara rendah dengan berpikir bahwa dirinya memang benar tidak kompeten, tidak mempunyai kelebihan, tidak sempurna, tidak berguna, dan tidak berharga (Liu, 2011). Adanya pikiran negatif tersebut membuat mereka merasa direndahkan, dikucilkan, diasingkan dan dicemooh oleh teman-temannya sehingga korban bullying beranggapan bahwa kehadirannya hanya dijadikan sebagai bahan bully. Situasi ini semakin mendorong korban bullying mengalami perilaku isolasi sosial (Lefler \& Cohen, 2014).

Isolasi sosial merupakan suatu keadaan dimana seseorang mengalami penurunan ketertarikan melakukan interaksi sosial sehingga menyebabkan minimnya kontak mata ketika melakukan komunikasi dengan orang lain (Kinsella, 2015). Seperti hasil penelitian yang telah dilakukan Sleglova dan Cerna (2011) mengungkapkan bahwa bentuk perilaku isolasi sosial yang dilakukan siswa setelah mendapatkan perilaku bullying seperti melarikan diri ketika bertatap muka secara langsung, memblokir seluruh kontak, menghapus pesan yang sifatnya mengancam bahkan sampai menolak untuk berangkat ke sekolah. Perilaku isolasi sosial yang terjadi terus menerus pada korban bullying dapat menimbulkan munculnya sikap acuh tak acuh, kurangnya perasaan empati, menurunnya kemampuan diri didalam mengekspresikan perasaan, keinginan, dan pendapat (Lefler \& Cohen, 2014). Kondisi ini semakin membuat mereka menjadi pribadi yang tertutup, menolak untuk terlibat dalam kegiatan sosial dan mendorong individu cenderung untuk menggantungkan pemenuhan kebutuhan hidupnya kepada orang lain (Hemingway \& Jack, 2013).

Berdasarkan paparan masalah yang telah diuraikan diatas, maka diperlukan tindakan segera untuk mengatasi permasalahan agar dapat terselesaikan dengan tepat. Tindakan yang mampu diterapkan untuk menangani kasus perilaku isolasi sosial yang dialami oleh korban bullying melalui pemberian psikoterapi yakni Social Skill Training (SST). SST merupakan suatu terapi yang mengajarkan seseorang untuk mampu melakukan sosialisasi dengan cara membangun keterampilan sosial sehingga dapat menciptakan hubungan positif dengan teman sebayanya (Koiv, 2012).

Seperti hasil penelitian yang telah dilakukan oleh Khalil (2012) menyatakan bahwa SST sangat efektif meningkatkan keterampilan sosial pada klien skizofrenia. Hal ini dapat terjadi karena melalui SST, klien akan dilatih berbagai perilaku baru seperti cara bercakap, keterampilan dalam memecahkan masalah, melatih ketegasan, dan melatih mengekspresikan pikiran serta perasaannya sehingga dapat menjaga hubungan interpersonal dengan orang lain secara adaptif.

Dari hasil studi pendahuluan yang dilakukan di SMK Ahmad Yani Probolinggo tanggal 20 Februari 2017 berdasarkan hasil wawancara dengan guru BK didapatkan bahwa prevalensi bullying di sekolah tersebut telah mencapai $90 \%$ dengan kelas $X$ mengalami prevalensi bullying lebih tinggi sebesar $42 \%$ dibandingkan kelas XI sebesar $31 \%$ dan XII yakni $27 \%$. Korban bullying mendapatkan perlakuan dalam bentuk seperti mengejek, mengolok nama dan orang tua korban, menyebarkan informasi yang tidak benar dihadapan orang lain, melakukan pengeroyokan. Selain itu, korban bullying terlihat menyendiri, pendiam, menunduk, pasif saat berada didalam maupun diluar kelas, menolak satu 
kelompok dengan pembully, mengalami kesulitan ketika menerima informasi saat berada didalam kelas bahkan malas untuk berangkat ke sekolah. Berdasarkan uraian data dan fakta tersebut, maka peneliti

\section{METODE PENELITIAN}

Penelitian menggunakan desain quasy experimental pre-post test design. Teknik penentuan sampel memakai purposive sampling dengan menetapkan siswa kelas $X$ SMK Ahmad Yani Probolinggo sebagai responden penelitian sesuai dengan kriteria inklusi meliputi bersedia menjadi responden, tidak mengalami kecacatan, orang tua utuh dan mengalami perilaku isolasi sosial akibat bullying dengan skor minimal $\geq 42$ berdasarkan pengukuran kuesioner menurut Keliat (2005); Stuart (2013). Sedangkan kriteria eksklusi yaitu tidak

\section{HASIL PENELITIAN}

\section{Karakteristik Responden}

Berikut ini adalah uraian hasil dari distribusi frekuensi karakteristik demografi respondensebagai berikut:umur responden yang mendapatkan intervensi SST yakni 16,50 dengan nilai signifikansinya adalah $\rho$ $=0,341$. Dengan demikian, perilaku isolasi sosial remaja korban bullying tidak dipengaruhi oleh umur. Sementara itu, jenis kelamin responden seluruhnya yaitu lakilaki sebanyak 18 orang (100\%). Sedangkan, pendidikan ayah mayoritas pendidikan dasar sebanyak 12 orang (67\%), nilai $p$-value sebesar 0,618 dan sebagian besar ayah bekerja sebanyak 17 tertarik melakukan pengembangan lebih lanjut tentangefektifitas SST didalam menurunkan perilaku isolasi sosial remaja korban bullying.

mengikuti sesi terapi secara penuh. Penelitian ini dilakukan di SMK Ahmad Yani Probolinggo mulai bulan Mei sampai Juni 2017. Sampel penelitian menggunakan rumus menurut Supranto (2000) yaitu (t1) $(r-1) \geq 15$ sebanyak 16 responden. Untuk mencegah drop out, maka ditambahkan $10 \%$ sehingga berjumlah 18 responden. Intervensi SST terdiri diri lima sesi terapi berlangsung selama 30-45 menit. SST dilakukan oleh peneliti sebab peneliti dengan adanya lisensi kelayakan terapi yang diberikan oleh perawat spesialis keperawatan jiwa. analisa data yang digunakan uji $t$-test berpasangan.

orang (94\%) dengan p-value yaitu 0,216 . Sementara itu, pendidikan ibu mayoritas pendidikan dasar sejumlah 14 orang $(78 \%)$, nilai $p$-value sebesar 0,250 . Pekerjaan ibu mayoritas sama-sama sebagai pekerja dan tidak bekerja sebanyak 9 orang (50\%), nilai $p$-value sejumlah 0,865 . Sedangkan penghasilan keluarga mayoritas bergolongan bawah sebanyak 15 orang (83\%) dan p-value sebesar 0,909. Berdasarkan hasil tersebut, seluruh nilai sigifikansi $\rho \geq 0,05$ artinya bahwa pendidikan, pekerjaan serta penghasilan keluarga tidak terdapat hubungan yang bermakna dengan perilaku isolasi sosial remaja.

\section{Analisa Univariat}

\subsection{Perilaku Isolasi Sosial Remaja Korban Bullying}

Tabel 1. Distribusi Rata-Rata Skor Perilaku Isolasi Sosial Sebelum dan Sesudah SST

\begin{tabular}{|c|c|c|c|}
\hline \multirow{2}{*}{ Intervensi } & \multirow{2}{*}{$\mathbf{n}$} & \multicolumn{2}{|c|}{$\begin{array}{l}\text { Skor Perilaku Isolasi sosial } \\
\qquad x \pm \text { SD }\end{array}$} \\
\hline & & Sebelum & Sesudah \\
\hline SST & 18 & $79,11 \pm 8,04$ & $58,83 \pm 8,55$ \\
\hline
\end{tabular}

Data diatas diperoleh perilaku isolasi sosial sebelum SST 79,11. Sementara itu, setelah responden diberikan SST, skor rata-rata perilaku isolasi sosial mencapai 58,83 sehingga mengalami penurunan sebesar 20,28. 


\section{Analisis Bivariat \\ 2.2 Pengaruh SST Terhadap Penurunan Perilaku Isolasi Sosial Remaja Korban Bullying}

Berdasarkan hasil uji normalitas diperoleh nilai signifikasi dari shapiro, skor perilaku isolasi sosial sebelum dilakukan SST adalah $\rho=0,431$ dan setelah perlakuan yaitu $\rho=0,192$. Berdasarkan data tersebut, maka dapat diketahui bahwa seluruh nilai signikansi $\rho \geq 0,05$ artinya seluruh data mempunyai sebaran normal.

Tabel 2. Perbedaan Rerata Skor Perilaku Isolasi Sosial Remaja Korban Bullying

\begin{tabular}{cccc}
\hline Perilaku Isolasi Sosial & $\mathbf{n}$ & $\mathbf{X} \pm \mathbf{S D}$ & $\mathbf{p}$ \\
\cline { 1 - 3 } Pre-test & 18 & $79,11 \pm 8,04$ & \multirow{2}{*}{0,000} \\
\hline Post-test & 18 & $58,83 \pm 8,55$ & \\
\hline
\end{tabular}

Didapatkan bahwa skor perilaku isolasi pada saat sebelum dan sesudah diberikan SST diketahui mengalami penurunan skor perilaku isolasi sosial sebesar 20,28 dari yang awalnya yakni sebesar 79,11 menurun menjadi 58,83 dengan nilai signifikansi sebesar $\rho=0,000$ sehingga nilai $\rho \leq 0,05$. Dengan demikian dapat dikatakan bahwa terdapat perbedaan rerata skor perilaku isolasi sosial pada saat sebelum dan sesudah diberikan intervensi SST.

PEMBAHASAN

\section{Perbedaan Perilaku Isolasi Sosial Remaja Korban Bullying Sebelum dan Sesudah SST}

Hasil penelitian didapatkan bahwa nilai skor rata-rata perilaku isolasi sosial yang dialami oleh responden mengalami penurunan setelah mendapatkan intervensi SST. Hal ini ditunjukkan dengan nilai skor rata-rata perilaku isolasi sosial sebelum diberikan intervensi sebesar 79,11 dan 58,83 skor sesudah diberikan intervensi. Sesuai dengan hasil tersebut, maka dapat diketahui bahwa perilaku isolasi isosial yang dialami responden mengalami penurunan sebesar 20,28 dan nilai signikansinya $\rho=0,000$ sehingga $\rho \leq 0,05$ artinya terdapat perbedaan antara skor perilaku isolasi sosial secara bermakna pada saat sebelum dan sesudah diberikan intervensi SST. Dengan demikian, maka dapat dikatakan bahwa SST dapat menurunkan perilaku isolasi sosial yang dialami remaja akibat mendapatkan perlakuan bullying.

Hasil penelitian tersebut sesuai dengan pernyataan yang diungkapkan oleh Gundersen (2010) bahwa prinsip kerja SST adalah menitikberatkan terhadap kemampuan melakukan komunikasi, mendorong untuk dapat melakukan interaksi timbal balik, dan melatih agar mampu terlibat didalam memutuskan dan bertindak sehingga dapat memecahkan permasalahan yang dialaminya terutama dengan orang lain. Dengan demikian mereka dapat mempertahankan hubungan sosial ketika berada dalam situasi apapun. Seluruhnya dapat terwujud dengan cara melatih keterampilan baru didalam bersosialisasi seperti melatih interaksi sosial secara non verbal seperti membangun kontak mata dan ekspresi wajah, menyapa orang lain secara verbal sambil memperhatikan volume, kecepatan, dan nada suara, mampu mengungkapkan perasaan dan dapat menjadi pendengar dengan baik.

Pemberian SST diberikan kepada responden penelitian sebab mayoritas responden selalu terlihat murung, menolak untuk berkumpul bersama dengan temantemannya, selalu menunduk, diam, pasif ketika berada didalam maupun diluar kelas, menolak untuk satu kelompok dengan teman yang selalu membully kepadanya, tidak mau menyapa orang lain yang tidak dikenal sebelumnya, lebih suka menyendiri agar tidak dibully oleh temen-temannya. Perilaku tersebut dilakukan oleh korban bullying karena mereka tidak mempunyai kemampuan dan keberanian untuk mengutarakan pikiran dan perasaan yang mereka alami akibat dari perlakuan bullying yang diterimanya. Korban bullying merasa bahwa dirinya tidak berdaya terhadap penilaian negatif yang diungkapkan oleh teman sebayanya sehingga mereka hanya berespon diam dan membiarkan begitu saja ketika orang lain melakukan bully terhadap dirinya. Melalui SST inilah, responden mendapatkan pelatihan beberapa macam kegiatan baru antara lain meliputi 
mempelajari keterampilan cara menjalin perkenalan dengan orang lain melalui interaksi verbal maupun non verbal, berlatih membina dan memelihara pertemanan, mempelajari cara menyampikan pendapat, perasaan, kritik, penolakan, menerima masukan, dan memberikan serta menerima pujian dari orang lain. Tentunya, seluruh kegiatan tersebut memerlukan latihan dan komitmen dari responden untuk berlatih secara terus menerus (Gresham, Van dan Cook, 2006).

Pernyataan serupa juga disampaikan oleh Assunta (2013) mengutarakan bahwa SST juga lebih berfokus kepada aspek pengubahan perilaku seperti membangun kembali rasa empati, mampu mengevaluasi dan melakukan introspeksi diri dengan sikap jauh lebih terbuka yang dapat diutarakan baik dalam bentuk verbal maupun non verbal, serta dapat memahami dan peka terhadap isyarat perilaku yang dilakukan oleh orang lain. Pada SST, keterampilan non verbal juga akan dilatih sebab tidak bisa dipungkiri bahwa keterampilan non verbal sering kali dianggap sebagai suatu aspek yang dikesampingkan ketika menjalin interaksi dengan orang lain. Akan tetapi, keterampilan non verbal seperti kontak mata dan senyum justru menjadi indikator yang menunjukkan sikap sopan santun serta keramahan merupakan langkah awal ketika akan membina hubungan interpersonal.

Selain itu, seseorang akan dilatih pula cara untuk menjaga keseimbangan interaksi sosial secara lebih interaktif dengan memberikan penguatan mengenai pentingnya bersosialisasi dengan orang lain sehingga mereka dapat menerima kelebihan dan kekurangan yang dimiliki antar sesama. Adanya kemampuan inilah membuat individu tersebut dapat memelihara dan menjaga hubungan sosial dengan orang lain secara adaptif (Hotton dan Coles, 2016).

Menurut Gundersen (2010) juga menegaskan bahwa hasil akhir yang didapatkan dari SST ini dapat dinilai dari kemampuan individu memelihara dan menjaga perilaku agar sesuai dengan kaidah nilai serta moral yang berlaku dimasyarakat bahwa setiap individu saling memerlukan satu sama lain sehinggamereka dapat mencapai tujuan dan memperoleh pengalaman sosialisasi yang berharga dengan tetap saling menjaga dan menghargai hak setiap individu.

\section{IMPLIKASI KEPERAWATAN}

Temuan yang didapatkan ini merupakan bahan masukan bagi bidang ilmu keperawatan mengenai pemberian intervensi psikoterapi yaitu SST menjadi salah satu alternatif dalam mengatasi masalah psikososial terutama untuk menurunkan perilaku isolasi sosial pada remaja yang mendapatkan perlakuan bullying. Selain itu, pada institusi pendidikan terutama di SMK Ahmad Yani Probolinggo dapat digunakan sebagai salah satu solusi yang paling efektif bagi guru BK untuk menangani para siswa remaja yang sering mendapatkan perlakuan bullying dari teman sebayanya sehingga para siswa tersebut dapat tetap memelihara kesehatan emosionalnya dengan baik.

\section{KESIMPULAN}

Terdapat perbedaan penurunan perilaku isolasi sosial antara sebelum dan sesudah diberikan intervensi pada kelompok SST.

\section{SARAN}

Penerapan intervensi SST menjadi rujukan dalam menangani permasalahan psikososial terutama pada remaja agar dapat meningkatkan keterampilan sosial sehingga dapat mendorong keberhasilan dari proses tahap tumbuh kembang yang dialaminya. Sedangkanuntuk penelitian selanjutnyat diperlukan penelitian lanjutan dengan lebih menitikberatkan kepada karakteristik responden terutama jenis kelamin. Selain itu, perlu untuk memberikan intervensi kepada keluarga, guru, dan teman sebaya melalui terapi suportif agar dapat memberikan dukungan kepada remaja korban bullying untuk selalu menerapkan hasil dari pelaksanaan terapi yang telah diberikan sehingga semakin dapat menurunkan perilaku isolasi sosial yang dialami remaja korban bullying. 


\section{DAFTAR PUSTAKA}

Al-Saadoon, M., Al-Farsi, Y. M., Rizvi, S., Al-Sharbati, M., Al-Jabri, A., Almamari, S., . . Al-Adawi, S. (2014). The magnitude and impact of bullying among school pupils in Muscat, oman: A cross-sectional study. The Scientific World Journal, 1-11. doi: http://dx.doi.org/10.1155/2014/169737

Assunta, C. C. M. (2013). Practice evaluation report: A social skills training group for people with severegrade mental handicap. Discovery -

SS Student E-Journal, 2, 169-194.

Cook, C. R., Williams, K. R., Guerra, N. G., Kim, T. E., \& Sadek, S. (2010). Predictors of bullying and victimization in childhood and adolescence: A meta-analytic investigation. School Psychology Quarterly, 25, 65-83. doi:

Gresham, F. M., Van, M. B., \& Cook, C. R. (2006). Social skills training for teaching replacement behaviors: Remediating acquisition deficits in atrisk students. Behavioral Disorders, 31(4), 363-377.

Gundersen, K. K. (2010). Reducing behaviour problems in young people through social competence programmes The International Journal of emotional Education, 2(2), 48-62.

Hemingway, A., \& Jack, E. (2013). Reducing social isolation and promoting well being in older people. Quality In Ageing And Older Adults, 14(1), 25-36. doi

Hotton, M., \& Coles, S. (2016). The effectiveness of social skills training groups for individuals with autism spectrum disorder. Rev J Autism Dev Disord, 3, 68-81. doi: 10.1007/s40489-015-0066-5

Karina, Hastuti, D., \& Alfiasari. (2013). Perilaku bullying dan karakter remaja serta kaitannya dengan karakteristik keluarga dan peer group. Jurnal IImiah Keluarga \& Konseling, 6(1), 2029.

Keliat, B. A. (2005). Modul basic course community mental health nursing. Jakarta: University of Indonesia.
Khalil, A. I. (2012). A community based treatment: Impact of social skills training program on improving social skills among schizophrenic patients. World Applied Sciences Journal, 18(3), 370-378. doi: 10.5829/idosi.wasj.2012.18.03.6438

Kinsella, S. (2015). Older people and social isolation: A review of the evidence. Wirral Council Business and Public Health Intelligence Team, 1-16.

Koiv, K. (2012). Social Skills Training as a mean of improving intervention for bullies and victims. Procedia - Social and Behavioral Sciences, 45, 239 246.

doi:10.1016/j.sbspro.2012.06.560

Lefler, N. L., \& Cohen, M. D. (2014). Differences in social skills among cyberbullies, cybervictims, cyberbystanders, and those not involved in cyberbullying. Journal of Child \& Adolescent Behavior, 2(4),

Liu, J. (2011). Childhood bullying: A review of constructs, contexts, and nursing implications. Public Health Nurs, 28(6), 556-568. doi: 10.1111/j.15251446.2011.00972.x.

Shafer, K. S., \& Silverman, M. J. (2013). Applying a social learning theoretical framework to music therapy as a prevention and intervention for bullies and victims of bullying. The Arts in Psychotherapy, 40, 495-500.

Sleglova, V., \& Cerna, A. (2011). Cyberbullying in adolescent victims: Perception and coping. Cyberpsychology: Journal of Psychosocial Research on Cyberspace, 5(2), 1-9

Srisiva, R., Thirumoorthi, R., \& Sujatha, P. (2013). Prevalence and prevention of school bullying - a case study of coimbatore city, Tamilnadu India. International Journal of Humanities and Social Science Invention, 2(5), 36-45. 